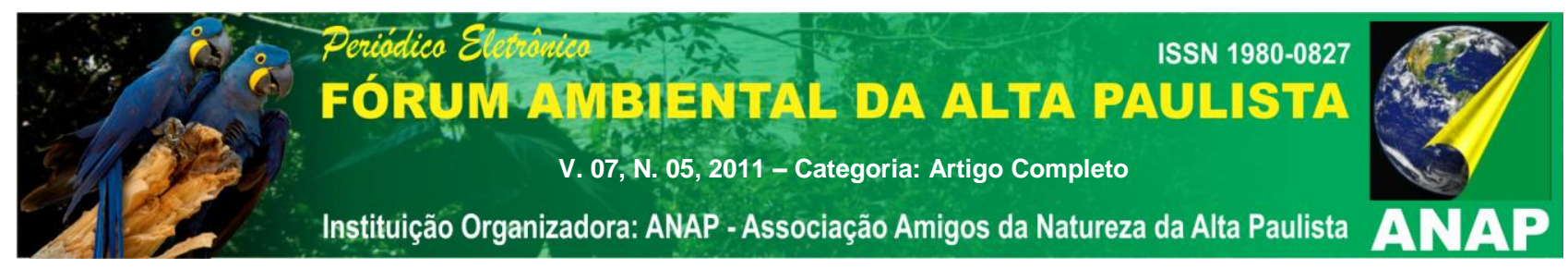

\title{
A HIDRELÉTRICA DE BELO MONTE SOB A ÓTICA DE UM JORNAL-LABORATÓRIO
}

\section{Silvana Aparecida de Paiva Rodrigues ${ }^{1}$}

RESUMO: O texto relata a experiência dos alunos do terceiro ano de Jornalismo da Fundação Educacional do Município de Assis - FEMA, na produção do jornal-laboratório Arte e Ação em que foram abordados os trâmites para a construção da usina hidrelétrica de Belo Monte, em Altamira (PA). A questão apresentada diz respeito àquilo que é considerado de interesse público pelos órgãos governamentais, e, principalmente, de como o tema foi articulado pelo jornal-laboratório Arte e Ação, haja vista ser uma forma de exercício para a prática jornalística dos alunos, abrindo espaço experimental para as técnicas profissionalizantes de captação, redação e edição de notícias, tendo como parâmetros o direito ambiental, a cidadania e práxis ética.

Palavras-chave: Jornal-laboratório; Cidadania; Ética.

\section{INTRODUÇÃO}

\footnotetext{
${ }^{1}$ Jornalista e docente do curso de Jornalismo da Fundação Educacional do Município de Assis - FEMA, nas disciplinas Edição Jornalística e Técnicas de Reportagem, Entrevista e Pesquisa Jornalística.
} 


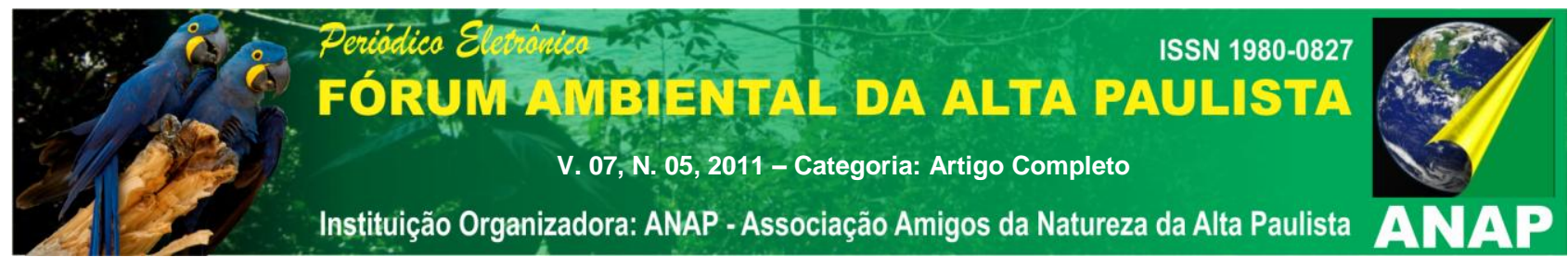

A princípio, em um curso de Jornalismo, aprender jornalismo seria o equivalente a fazer jornalismo. O jornal-laboratório serve, portanto, de exercício para a prática jornalística dos alunos, abrindo espaço experimental para as técnicas profissionalizantes de captação, redação e edição de notícias. Nesse sentido, o jornal Arte e Ação, mantido pelo curso de Jornalismo da Fundação Educacional do Município de Assis - FEMA, localizada em Assis, interior de São Paulo, além de servir como recurso de aprendizagem, também tem sido utilizado como instrumento para o exercício da cidadania.

Cidadania esta que tem assumido historicamente várias formas, em função dos diferentes contextos culturais. O conceito de cidadania, enquanto direito a ter direitos, tem se prestado a diversas interpretações. Porém, a definição que pretendemos expor é aquela definida como de "terceira geração", conforme Bredariol \& Vieira (2006, p. 23):

Trata-se dos direitos que tem como titular não o indivíduo mas grupos humanos como o povo, a nação, coletividade étnicas ou a própria humanidade. É o caso do direito à autodeterminação dos povos, direito ao desenvolvimento, direito à paz, direito ao meio ambiente etc. Na perspectiva dos 'novos movimentos sociais', direitos de terceira geração seriam os relativos aos interesses difusos, como o direito ao meio ambiente e o direito do consumidor, além do direito das mulheres, crianças, das minorias étnicas, dos jovens, dos anciãos etc.

Ainda como conceito de cidadania é imperativo destacarmos aqui o direito à comunicação, considerado por Ramos (2005, p. 247) como um novo direito social, que podemos considerar de "'quarta geração', aquele, quem sabe, mais adequado para amparar, nas sociedades da informação e da comunicação, nossas inesgotáveis expectativas de avanço crescente da democracia da igualdade em todo o mundo".

No intuito de fortalecer essa argumentação, Ramos (idem, p. 248), diz que:

O direito à comunicação constitui um prolongamento lógico do progresso constante em direção à liberdade e à democracia. Em todas as épocas históricas, o homem lutou para se libertar dos poderes que o dominavam, independentemente de que fossem políticos, econômicos, sociais ou religiosos, e que tentavam impedir a comunicação. Graças apenas a alguns esforços fervorosos e infatigáveis, os povos conseguiram a liberdade de palavra, de imprensa e de informação. Hoje em dia, prossegue a luta por estender os direitos humanos e conseguir que o mundo das comunicações seja mais democrático do que agora. 


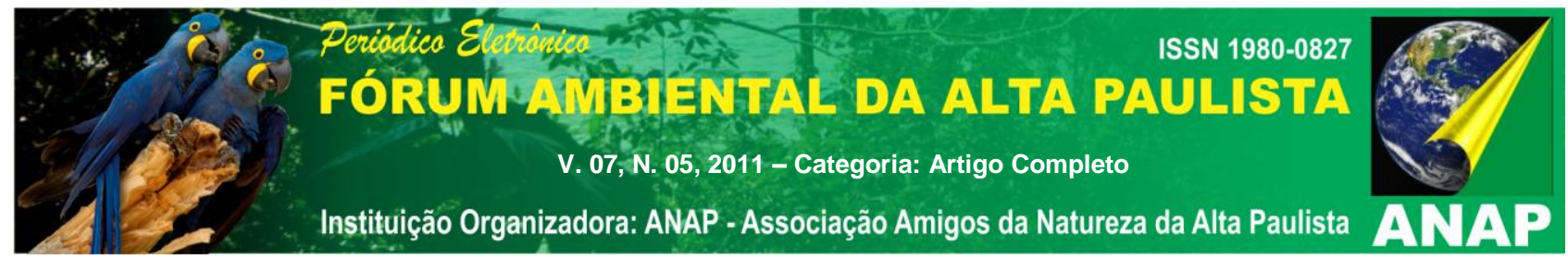

A partir dessas duas premissas, a da cidadania como direito a ter direito e a do direito à comunicação, como exercícios de liberdade e de democracia, é que são pautados e elaborados os jornais-laboratoriais do curso de Jornalismo da FEMA. É no terceiro ano do curso que os alunos produzem o jornal-laboratório Arte e Ação, em formato standart. São duas edições por ano, uma a cada semestre e a última, a 13a edição com oito páginas, foi elaborada no primeiro semestre de 2011 , abordando o tema "A Construção da Hidrelétrica Belo Monte no Pará".

\subsection{OBJETIVO}

O objetivo ao elaborar a pauta do jornal-laboratório foi, primeiro, o de promover a articulação teórico-prática, fundamental na formação do jornalista, de acordo com a Resolução no 03/78, aprovada pelo Conselho Federal de Educação, estabelecendo que as faculdades de jornalismo tivessem órgãos laboratoriais (LOPES, 1989: 23). Segundo porque, conforme defende Bucci (2008, p. 46), "sem o livre fluxo de informações e opiniões, o regime democrático não funciona, a roda não gira". E terceiro, pela decepcionante constatação de que poucas pessoas têm conhecimento do que se trata e as implicações da obra de Belo Monte.

A Hidrelétrica Belo Monte será a maior usina hidrelétrica inteiramente brasileira e a terceira maior do mundo, com estimativa de iniciar as operações no dia 28 de fevereiro de 2015. Segundo o Ministério de Minas e Energia, sua construção deve gerar cerca de 20 mil empregos diretos. A Belo Monte terá capacidade instalada de 11.233,1 MW de potência e geração anual prevista de 38.790.156 MWh ou 4, 5mil MW médios e reservatório com área de $516 \mathrm{~km}$ quadrados. A conclusão do empreendimento está prevista para 31 de janeiro de 2019. O empreendimento integra o Plano de Aceleração do Crescimento (PAC), prioridade do governo federal que, garante, com a entrada em ação da Belo Monte, propiciará mais oferta de energia e mais segurança para o Sistema Interligado Nacional (SIN), com melhor aproveitamento das diferenças hidrológicas de cheia e seca nas diversas regiões do País. 


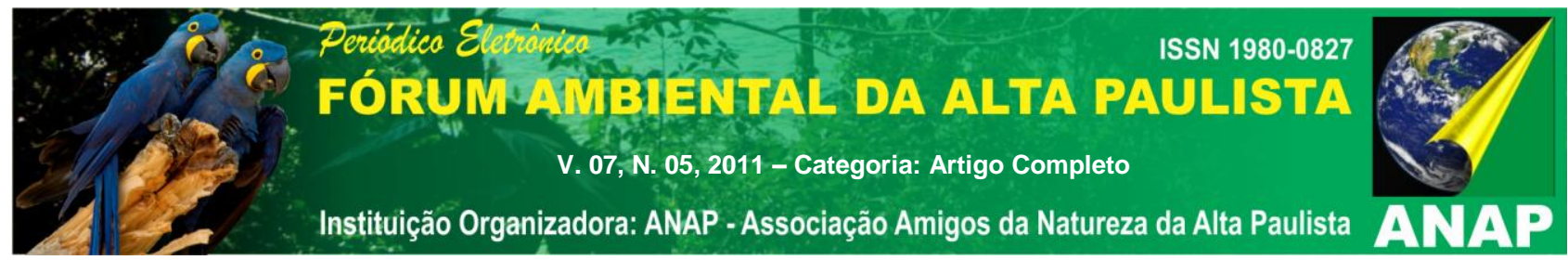

Pelo gigantismo da obra e pelas proporções econômica, ambiental e social que vai alcançar, tanto em nível regional como nacional, um fato permanece vexatoriamente irrisório: muitas pessoas não têm qualquer conhecimento sobre a Belo Monte ou qualquer outra informação do que está ocorrendo no Pará. Por meio de uma checagem apenas no meio acadêmico, sem nenhum teor científico de pesquisa, chegamos à constatação do desconhecimento e da desinformação a respeito da hidrelétrica. Reforçamos que não temos dados com fundamento científico, mas empírico com certeza.

\section{DESENVOLVIMENTO}

\subsection{O JORNAL-LABORATÓRIO}

Como já citamos anteriormente, a produção do jornal-laboratório é uma prática pedagógica determinada pela Resolução no 03/78, aprovada pelo Conselho Federal de Educação, estabelecendo que as faculdades de jornalismo tivessem órgãos laboratoriais. Em 1980 estabeleceu-se, através da Resolução no 01/79, que alterou 0 artigo 7ํㅜ e parágrafos $1^{\circ}$ e $2^{\circ}$, da Resolução $n^{\circ}$ 03/78, a vigência do ato normativo fixando as exigências curriculares e laboratoriais (LOPES, 1989: 23).

Como atividade curricular obrigatória, o jornal-laboratório Arte e Ação passou a ser espaço de aprendizado, de exercício de direitos e deveres, de difusão da informação, de plataforma para veiculação dos assuntos os mais variados, como o que foi pautado a respeito da construção da hidrelétrica Belo Monte. No entanto, não se tratava do cumprimento de uma tarefa pedagógica, simplesmente. Mas sim, de uma atividade articulada, imbuída do espírito propagador de comunicadores que somos, de acordo com o que defende Lopes (1989, p. 16):

Não basta, no entanto, publicar um jornal apenas para satisfazer a vaidade pessoal do aluno ou cumprir uma tarefa determinada pelo professor. É fundamental que um jornal-laboratório seja dirigido a uma determinada comunidade para ter um público definido e ser um vínculo com todas as características de um jornal profissional. Uma publicação que leve a comunidade a tomar consciência de seus problemas e a organizar-se para resolvê-los. Dessa forma o estudante de Jornalismo poderá ser realmente habilitado para o mercado de trabalho. 


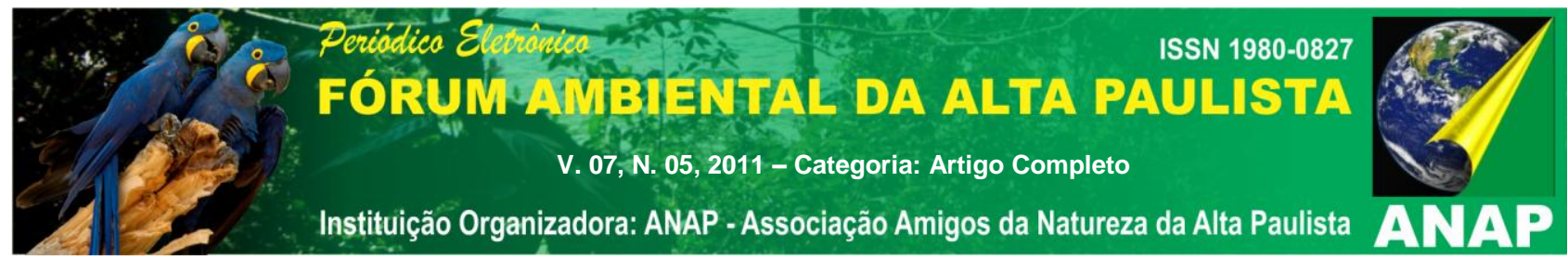

Entendemos, portanto, que é no meio acadêmico que o aluno deve receber o treino, através da didática aplicada no jornal-laboratório, onde é possível que se alie o processo de produção à reflexão do fazer jornalístico. Não basta apenas simular situações profissionais, mas também vivenciá-las tomando conhecimento de visão de conjunto ao que rege toda a estrutura do processo jornalístico na elaboração de um jornal impresso. É oportuno enfatizar que a preocupação na formação de um profissional responsável, crítico e ético deve ser o fio que conduz os critérios de produção e difusão do jornal-laboratório. Para corroborar essa premissa, citamos ainda o professor José Marques de Melo que diz:

O jornal-laboratório constitui espaço essencial de ensino aprendizagem para a formação de jornalistas na universidade. Sua função é a de criar ambiente propício para a reprodução dos processos jornalísticos, em situações práticas, vivenciadas pelos alunos, das quais os professores extraem evidências para explicar as teorias que embasam a profissão. (in: VIEIRA JUNIOR, 2002)

Quando falamos em direitos e deveres, devemos nos atentar também ao Código de Ética ${ }^{2}$ dos Jornalistas Brasileiros que vigora há 26 anos, sendo aprovado em 1985 pelo Congresso Nacional da categoria. Os debates para sua atualização foram iniciados em 2004 e as alterações foram definidas em congresso extraordinário e específico sobre o tema, precedido de consulta pública à sociedade, em 2007. Dentre as disposições preconizadas, há um roteiro de obrigações de comportamento, entre as quais:

É dever do jornalista combater e denunciar todas as formas de corrupção; divulgar todos os fatos que sejam do interesse público; lutar pela liberdade de pensamento e expressão; opor-se ao arbítrio, ao autoritarismo e à opressão; defender os princípios expressos na Declaração Universal dos Direitos Humanos. (ALCANTARA, 2005, p.9)

E exatamente por todos estes argumentos expostos acima que defendemos o jornal-laboratório como uma iniciativa imprescindível que, com o tempo, deixa de ser mero exercício escolar e passa a adquirir uma importância pedagógica e socialmente relevante. Embora a experiência do jornal-laboratório Arte e Ação seja restrita mais à comunidade

\footnotetext{
2. Disponível em <www.fenaj.org.br/>. Acesso em maio de 2011.
} 


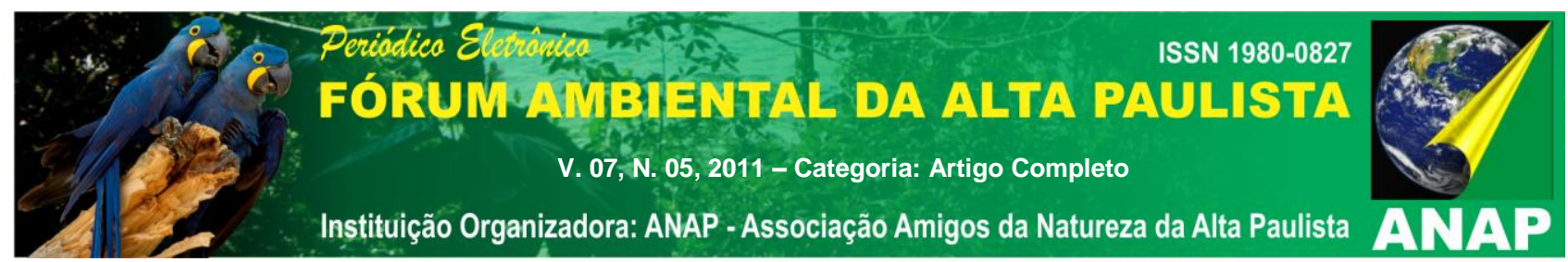

acadêmica, acreditamos ter sido possível a disseminação de uma informação até então conhecida por poucos: a construção da Usina Hidrelétrica de Belo Monte e suas implicações sociais, ambientais e econômicas.

\subsection{RESPONSABILIDADE SOCIAL}

Muito mais que a prática acadêmica, o jornal-laboratório traz em sua essência o exercício da cidadania. $O$ direito à informação e à comunicação vem sendo proclamado como fundamental, desde as primeiras declarações de direitos o século 18. Para melhor cumprir seu papel de levar informações ao cidadão, a imprensa, considerado aí o jornallaboratório como tal, precisa fiscalizar o poder. Segundo Bucci, o verbo fiscalizar carrega aqui, o sentido de vigiar, de limitar o poder:

Sem ela [a imprensa], não há como se pensar em limites para o exercício do poder da democracia. Portanto, não é saudável e nem útil a imprensa que se contente com o papel de apoiar os que governam. Não é saudável, não é útil, nem mesmo imprensa ela é (BUCCI, 2008: p. 46).

A idéia não é, porém, fazer oposição apenas para ser contrário ao governo, mas sim de estabelecer um diálogo sobre a responsabilidade social do jornalista. E no caso da hidrelétrica Belo Monte, fomos desafiados pelo o que percebemos como falta de informação ou desinformação propriamente dita, há vista que nem mesmo os meios de comunicação de massa como jornais, rádio e televisão tem pautado o tema com a frequência e o destaque necessários para maior esclarecimento sobre 0 assunto pela população, tanto a do local onde será construída a usina, em Altamira - PA, no Rio Xingu, como a de nível nacional. Neste sentido, Bucci faz um alerta:

Por aqui, ainda nos encontramos longe de tratar o direito à informação no nível dos demais direitos, como a educação ou a saúde, o que é trágico: onde esse direito não se faz respeitar integralmente, a liberdade necessária para bem informar a sociedade não pode ser exercida plenamente (BUCCI, 2008: p. 47). 


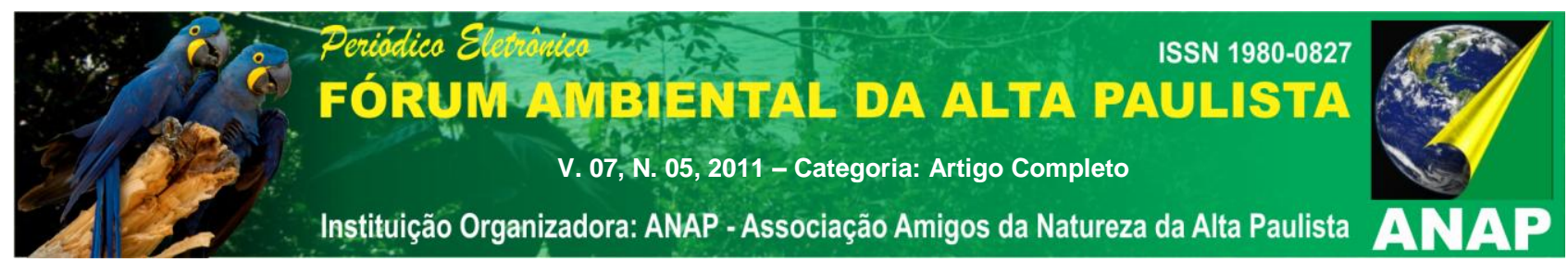

A construção da Usina Hidrelétrica Belo Monte tem repercutido mais nas redes sociais, conforme pudemos constatar ao fazer as pesquisas sobre prováveis fontes para a produção das matérias. Uma das reportagens feitas foi exatamente a respeito de uma empresa especializada em monitoramento da audiência na internet, a MITI Inteligência que, além de viabilizar o debate sobre o assunto a internet tem proporcionado às pessoas outras fontes de informação. A empresa MITI Inteligência ${ }^{3}$ faz o monitoramento de mídias online e mídias sociais, sendo que estas últimas representam uma área movimentada para qualquer debate, principalmente quando se fala em questões ambientais, como as que envolvem a construção da usina Belo Monte.

A plataforma analisa determinado tema por meio de seu reflexo quantitativo nas mídias online por palavra-chave. O site realizou um monitoramento acerca do termo "Belo Monte" durante cinco dias nas redes sociais, de 27 a 31 de janeiro de 2011. O objetivo era o de observar a repercussão que o assunto vem ganhando no mundo virtual. Para vias de comparação, o site também monitorou as palavras-chave "Itaipu", "Hidrelétrica" e "Termelétrica". A palavra-chave Belo Monte foi a mais pesquisada, com $72 \%$ das buscas.

Outro monitoramento feito pela MITI no mesmo período foi com relação à aprovação ou reprovação quanto à construção da hidrelétrica Belo Monte. A conclusão do monitoramente é a de que a desaprovação da obra por parte dos internautas é recorde. Por meio do monitoramento, foi possível detectar, também de acordo com as informações da MITI, que entre Organizações Não Governamentais - ONGs -, políticos, jornalistas e celebridades são muitas as mobilizações contra a construção da hidrelétrica. Cerca de $85 \%$ dos internautas monitorados se manifestaram contra a Belo Monte. Das palavras monitoradas, foram registradas mais de 20.477 interações, das quais 7.310 foram sobre "Belo Monte". Das notícias monitoradas, no total de 2.675, a palavra-chave "Belo Monte" aparece 526 vezes.

\subsection{O PROCESSO DE PESQUISA, ENTREVISTA E EDIÇÃO}

\footnotetext{
${ }^{3}$ Disponível em <http://miti.com.br>. Acesso em junho de 2011.
} 


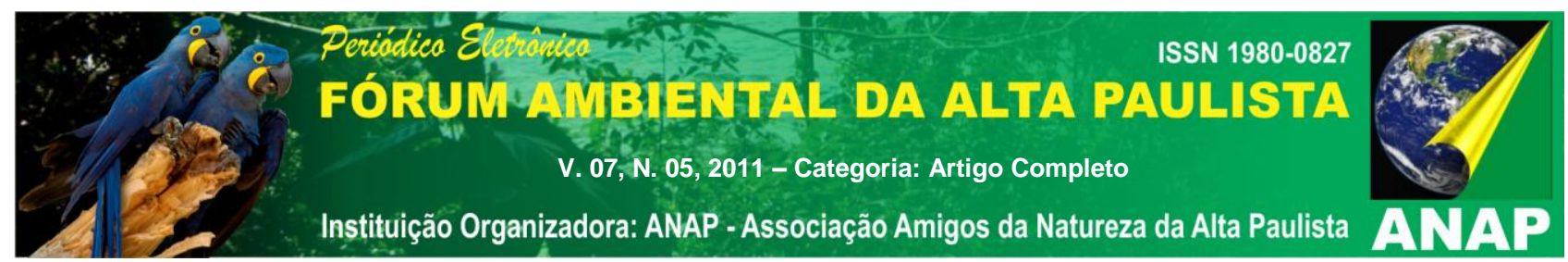

O jornal-laboratório Arte e Ação está em sua $13^{\text {a }}$ edição e já tem projeto gráfico definido desde a primeira impressão, em 2004. É em formato standart ${ }^{4}$, largamente utilizado pelos jornais de maior circulação nacional, como a "Folha de S. Paulo", por exemplo, em função do aproveitamento máximo da área de chapa das offset $t^{5}$. Nesse formato, a mancha gráfica da página mede 52,5 por 29,7 centímetros. A área total de papel depois de impresso é de 56 por 32 centímetros. Para a confecção, é necessário equipamento de impressão rotativo, disponível em grande editora e parque gráfico de jornais diários e periódicos de grande circulação. $O$ formato standard segue a diagramação modular que mescla a distribuição vertical com a distribuição horizontal das matérias em busca de um layout de página dinâmico e atraente para o leitor. A escolha por este formato é justamente para que os alunos tenham acesso a este tipo de formatação mais comum no mercado editorial de jornais no Brasil.

Logo no início do semestre de cada ano letivo, são definidos o tema a ser abordado e as pautas a serem desenvolvidas por cada aluno. A escolha da pauta variavelmente é feita pelo próprio aluno ou definida pelo professor, tudo de acordo com o tema central.

A pauta é o planejamento de uma edição ou parte da edição, com a listagem dos fatos a serem cobertos e dos assuntos a serem abordados em reportagens, "além de eventuais indicações logísticas e técnicas: ângulo de interesse, dimensão pretendida da matéria, recursos disponíveis para o trabalho, sugestões de fontes etc", de acordo com a definição de Lage (2002, p. 34) que esclarece:

É claro que o êxito de uma pauta depende essencialmente de quem a executa. $O$ trabalho de reportagem não é apenas o de seguir um roteiro de apuração e apresentar um texto correto. Como qualquer projeto de pesquisa, envolve imaginação, insight: a partir dos dados e indicações contidos na pauta, a busca do ângulo (às vezes sugerido ou nem isso) que permita revelar uma realidade, a

\footnotetext{
${ }^{4}$ Standard - Tamanho padrão dos jornais. Mede $56 \mathrm{~cm}$ de altura por $32 \mathrm{~cm}$ de largura (fechado e impresso). O único caso no Brasil de jornal que conseguiu sucesso sem ser standard é o Zero Hora, de Porto Alegre, publicado em tamanho tablóide. O tamanho tablóide é a metade do standard. Disponível em <http://pt.scribd.com/doc/5665533/Glossario-de-Jornalismo>. Acesso em setembro de 2011.

${ }^{5}$ A expressão offset vêm de "offset litography" (literalmente, litografia fora-do-lugar), fazendo menção à impressão indireta (na litografia, a impressão era direta, com o papel tendo contato direto com a matriz). $O$ offset é um dos processos de impressão mais utilizados pois é ideal para grandes quantidades de impressos. O papel corre pela máquina, sem a intervenção humana enquanto o processo é feito. Mesmo assim, a máquina precisa de vários ajustes durante a impressão, seja na quantidade de tinta e água ou seja na hora em que um impresso for ter mais de uma cor. Disponível em < http://design.blog.br/design-grafico/oque-e-uma-impressao-offset-revisto>. Acesso em setembro de 2011.
} 


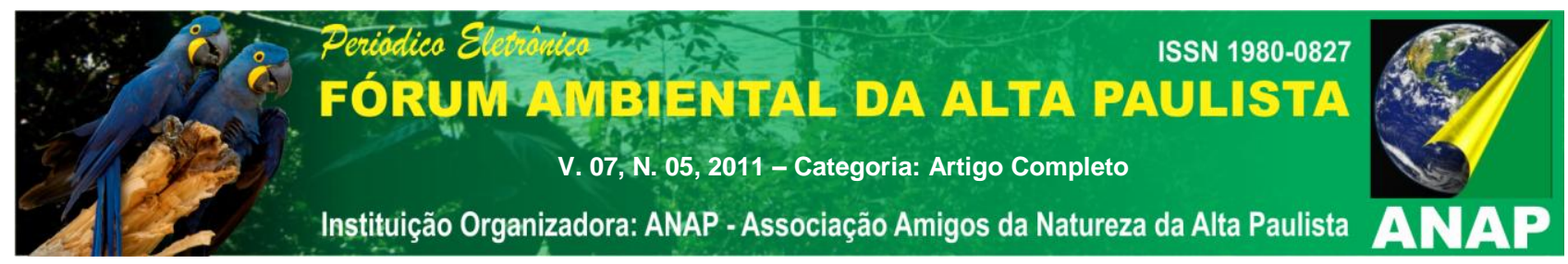

descoberta de aspectos das coisas que poderiam passar despercebidos (LAGE, 2002: p.35).

Além das pautas, foram determinadas as fontes de investigação, já que dificilmente matérias jornalísticas originam-se integralmente da observação direta. A maioria contém informações fornecidas por instituições ou personagens que testemunham ou participam de eventos de interesse público. As fontes escolhidas para o tema Belo Monte foram profissionais liberais como professores, advogados, historiadores, pesquisadores do meio ambiente e presidentes locais (de Assis) de órgãos como a Ordem dos Advogados do Brasil - OAB, por exemplo.

Determinada esta etapa, os alunos passaram para a realização das entrevistas, definida por Lage (2002, p. 73) como "o procedimento clássico de apuração de informações em jornalismo" ou ainda como "uma expansão da consulta às fontes, objetivando geralmente, a coleta de interpretações e reconstituições de fatos" (idem). Do ponto de vista dos objetivos, as entrevistas foram temáticas com a abordagem de um tema central, a construção da usina Belo Monte, e sub-temas a ele relacionados. Quanto à circunstância de realização, as entrevistas foram dialogais, a entrevista por excelência, na definição de Lage (2002, p 77):

Marcada com antecipação, reúne entrevistado e entrevistador em ambiente controlado (...) Entrevistador e entrevistado constroem o tom da conversa, que evolui a partir de questões propostas pelo primeiro, mas não se limitam a esses tópicos: permite-se o aprofundamento e o detalhamento dos pontos abordados.

A maior dificuldade dos alunos foi com relação à distância geográfica de Belo Monte, lá no Pará, e dos centros decisórios a respeito de licitação e licença ambiental, por exemplo, lá em Brasília. Diante deste fato, houve a necessidade de se aliar a entrevista à pesquisa por meio da internet, com acessos a sítios especializados em meio ambiente, blogs e até mesmo os sítios institucionais como o do lbama (Instituto Brasileiro do Meio Ambiente e dos Recursos Naturais Renováveis) e da empresa Norte Energia S.A., vencedora da licitação para a construção da hidrelétrica.

Além dos sítios de busca primária - que varrem a rede coletando referências às palavras-chave - existem outros que fazem a mesma investigação nos sítios de busca primária, remetendo ao que foi indexado pelos diferentes equipamentos de busca, 


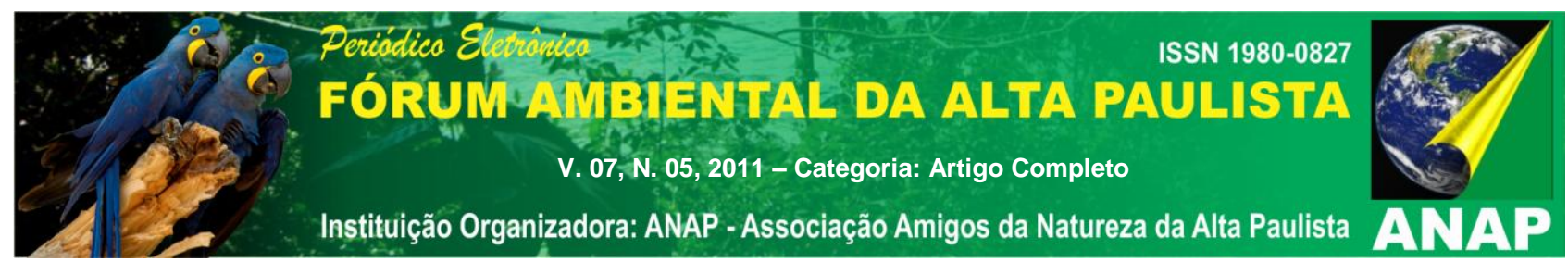

coletando relações ainda maiores. Foi grande o esforço aplicado pelos alunos no refinamento das buscas, cruzando referências ou especificando melhor os temas.

Feitas as entrevistas e as pesquisas, deu-se início ao trabalho de redação das reportagens. Dos gêneros jornalísticos, a reportagem foi considerada mais apropriada para a abordagem do tema em questão do que a notícia. Faz-se necessário, portanto, esclarecer a diferença entre reportagem e notícia. A reportagem é um texto mais extenso, resultante de uma investigação mais detalhada dos fatos, apresentando as informações em maior profundidade. Já a notícia é a informação exata e oportuna dos acontecimentos, opiniões e assuntos de todas as categorias que interessam aos leitores, ou seja, abordam os fatos essenciais de tudo o que aconteceu.

Com o intuito de diferenciar a reportagem da notícia, Lage busca caracterizar a reportagem, sob vários aspectos:

De acordo com a linguagem, a reportagem possui estilo menos rígido que a notícia, possibilitando ao repórter o uso da primeira pessoa, bem como fazer, além do levantamento de dados, interpretação dos fatos; sob o ponto de vista da produção, a reportagem leva em consideração a "oportunidade jornalística" (o fato gerador de interesse); a necessidade de pautas que incluam o fato gerador de interesse, a natureza da matéria e o contexto (LAGE, 2002:120).

Após esta última definição pela reportagem e não pela notícia, fechamos o ciclo de trabalho. Este ciclo, ressaltamos, foi desde a decisão, junto aos alunos, sobre o assunto a ser trabalhado; a divisão da classe em equipes de trabalho de acordo com a pauta de cada aluno; a discussão sobre a forma de levantar os dados sobre o assunto escolhido e a opção por periódicos, pesquisas de campo, como entrevistas, enquetes, fotos, pesquisa na internet etc; avaliar e selecionar os dados obtidos e organiza-los já tendo em vista a reportagem final; a correção e revisão dos textos adotando o sistema de troca, ou seja, um aluno revisando o texto de outro aluno; até a tarefa final que foi a diagramação ${ }^{6}$ do material, de acordo com o formato do jornal-laboratório Arte e Ação que é o standart.

\footnotetext{
${ }^{6}$ Diagramação - Adequação dos textos, desenhos, gráficos e fotos numa página, de acordo com os padrões visuais da publicação. Disponível em <http://pt.scribd.com/doc/5665533/Glossario-de-Jornalismo>. Acesso em setembro de 2011.
} 


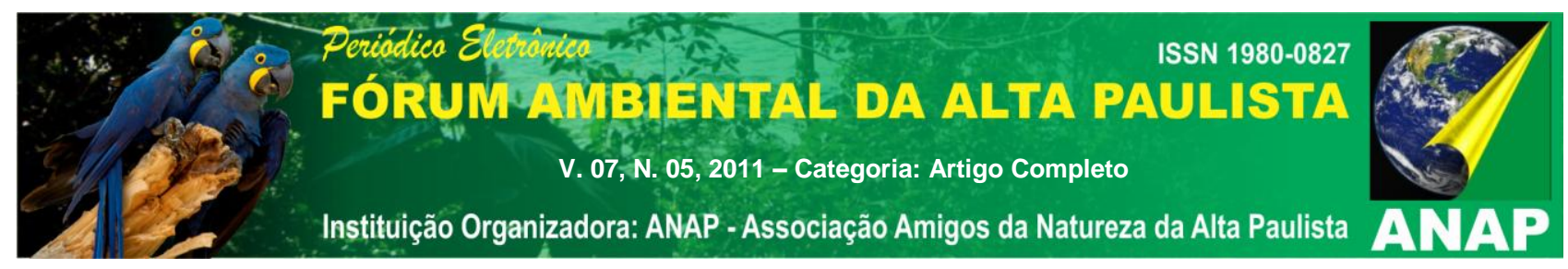

Os alunos também têm participação direta na proposta de diagramação que é a organização das reportagens, fotos, infográficos, títulos, subtítulos etc. A primeira proposta é, com as matérias finalizadas em mãos, que os alunos confeccionem o que chamamos de "boneco", feito à mão, com desenhos livres, como uma prévia do será a diagramação definitiva. A diagramação segue os objetivos e as linhas gráficas e editoriais do impresso. As principais linhas editoriais para a diagramação incluem a hierarquização das matérias por ordem de importância. Já as considerações gráficas incluem legibilidade e incorporação equilibrada e não obstrutiva dos elementos como texto, título, foto, arte, vinheta, box ou caixa, fio, cabeçalho e anúncio. No caso do jornal-laboratorial Arte e Ação não há a inclusão de anúncio, o que ocorreu somente nesta última edição com um anúncio institucional da FEMA no rodapé da primeira página.

Outra novidade desta $13^{\mathrm{a}}$ edição foi a utilização de uma charge, criada por um dos alunos. Até então, esse era um recurso que sempre esteve em falta, por não ter entre os discentes, o chargista. Na definição do Aurélio", charge é a "representação pictórica de caráter burlesco e caricatural em que se satiriza uma idéia, situação ou pessoa".

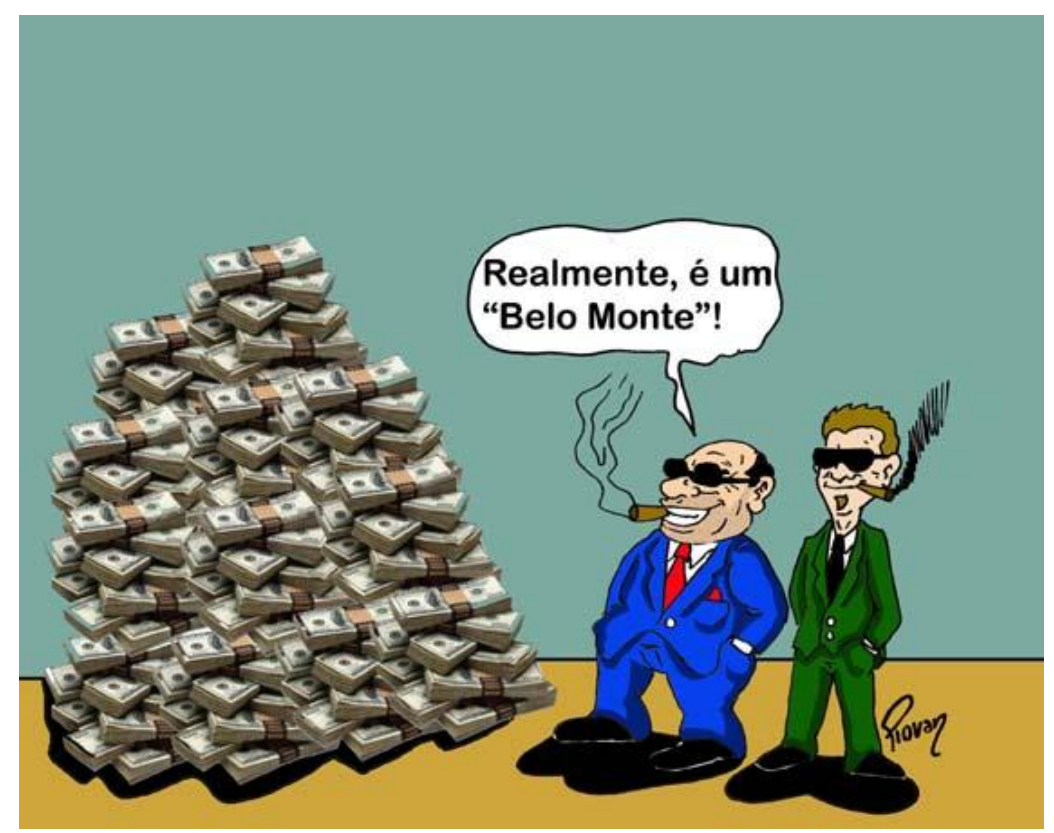

Charge criada pelo aluno de Jornalismo, Renato Piovan Publicada no jornal-laboratório Arte e Ação, edição ํำ 13, agosto de 2011

\footnotetext{
${ }^{7}$ Dicionário Aurélio online, disponível em <http://www.dicionariodoaurelio.com/>. Acesso em setembro de 2011.
} 


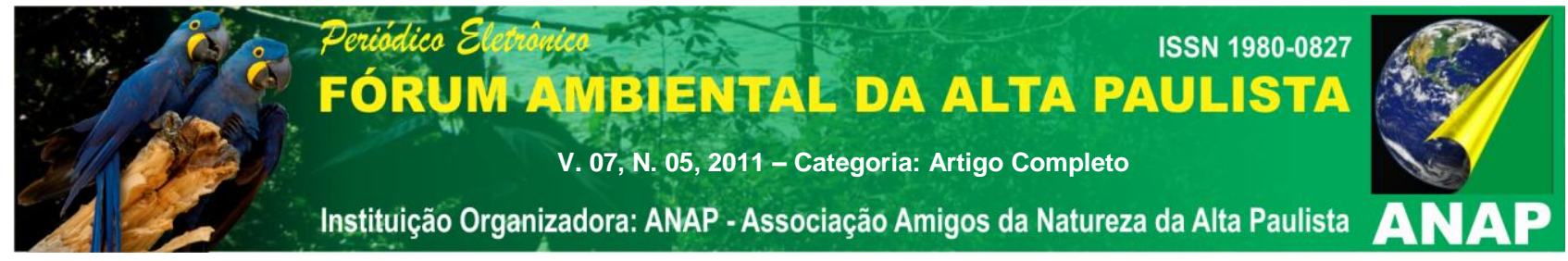

Chegamos, então, ao fechamento que é a etapa do processo de edição em que os trabalhos são encerrados, não há mais revisão do texto e a edição é enviada para a gráfica. Depois de impresso, o jornal é distribuído no meio acadêmico, encaminhado aos entrevistados e distribuído entre os próprios alunos para que o levem a outras pessoas de seu círculo de convívio, seja o familiar ou de amizades.

\subsection{A HIDRELÉTRICA DE BELO MONTE ${ }^{8}$}

Não poderíamos deixar de reservar um capítulo para um breve histórico a respeito do que se trata a construção da hidrelétrica de Belo Monte. A polêmica em torno da construção da usina, na Bacia do Rio Xingu no Pará, dura mais de 30 anos. Entre idas e vindas, atualmente é considerada a maior obra do Programa de Aceleração do Crescimento (PAC), do governo brasileiro. Desde 2009, quando foi apresentado o novo Estudo de Impacto Ambiental (EIA), intensificaram-se as críticas ao projeto, principalmente em 2010 quando o Ministério do Meio Ambiente concedeu a licença ambiental prévia para sua construção. No início do de junho de 2011, o Ibama (Instituto Brasileiro do Meio Ambiente e dos Recursos Naturais Renováveis) concedeu à Norte Energia (Nesa), a Licença de Instalação que autoriza a construção da hidrelétrica Belo Monte, no rio Xingu, próximo a Altamira (PA). O Projeto Belo Monte visa à construção de uma usina hidrelétrica prevista para ser implementada em um trecho de 100 quilômetros no Rio Xingu, no Pará. Atualmente, seu custo é estimado em $\mathrm{R} \$ 30$ bilhões, e potencial nominal de 11,2 mil MW, o que fará dela a maior usina hidrelétrica inteiramente brasileira. A usina de Itaipu, por exemplo, não é considerada totalmente brasileira porque está localizada na fronteira entre Brasil e Paraguai. A previsão é de que a Belo Monte será a terceira maior hidrelétrica do mundo, atrás apenas da chinesa Três Gargantas e da binacional Itaipu.

De acordo com o site da Agência Brasil, esta hidrelétrica terá um lago, o reservatório com área de 516 quilômetros quadrados. Serão construídas duas casas de força, a principal e a complementar. A primeira será construída no Sítio Belo Monte e terá uma potência de 11 mil MW. A complementar será construída junto ao reservatório

\footnotetext{
${ }^{8}$ Estas informações foram pesquisadas nos sites: <http://agenciabrasil.ebc.com.br>, <http://www.carta capital.com.br>, <http://www.blogbelomonte.com.br/> e <www.ibama.gov.br>, no período que foi de abril a agosto de 2011 .
} 


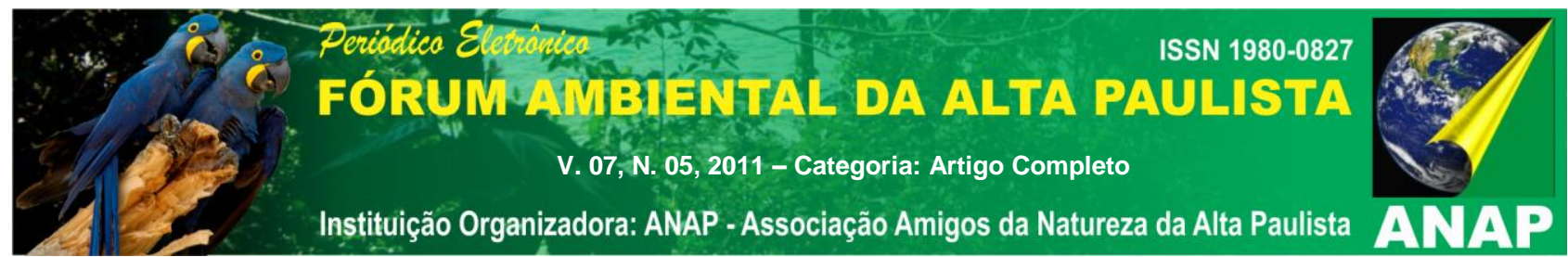

do Xingu, com potência de 233,1 MW. A área inundada pertence a terras dos municípios de Vitória do Xingu, Brasil Novo e Altamira. A energia produzida pela usina terá a capacidade de abastecimento para uma região estimada de 26 milhões de habitantes, com perfil de consumo elevado como a região metropolitana de São Paulo.

O projeto prevê a construção de uma barragem principal no Rio Xingu, 40 km abaixo da cidade de Altamira, no Sítio Pimental, sendo que o reservatório do Xingu localiza-se no Sítio Bela Vista. A partir deste reservatório, a água será desviada por canais de derivação que formarão reservatórios de canais localizados a $50 \mathrm{~km}$ de Altamira. O chamado Trecho de Vazão Reduzida, que foi assim denominado pelo relatório de Impacto Ambiental, estará localizado entre o reservatório do Xingu e a casa de força principal, correspondente a um comprimento de $100 \mathrm{~km}$, e terá a vazão reduzida em decorrência do desvio dos canais. Está previsto que este trecho deverá ser mantido com um nível mínimo de água, variável ao longo do ano. Este nível será controlado pelo Hidrograma Ecológico do Trecho de Vazão Reduzida, e tem como finalidade assegurar a navegabilidade do rio e condições satisfatórias para a vida aquática.

Ao conceder à Norte Energia (Nesa), a Licença de Instalação que autoriza a construção da usina hidrelétrica Belo Monte, o Ibama alegou que "o licenciamento foi marcado por uma robusta análise técnica e resultou na incorporação de ganhos socioambientais. Entre eles, a garantia de vazões na Volta Grande do Xingu suficientes para a manutenção dos ecossistemas e dos modos de vida das populações ribeirinhas."

\section{CONCLUSÃO}

Por princípio ético, articulamos a produção do jornal-laboratório Arte e Ação para que não transparecesse nenhuma posição contra ou a favor da construção da usina Belo Monte. O ser imparcial, algo tão difícil de levar à prática. Porém, nos encontramos diante de uma situação em que, por sermos seres que se constroem criticamente, vocacionados para a liberdade, não conseguimos deixar essa questão de lado, "em nome de um pragmatismo cínico que lamenta as desigualdades apenas para aceitá-las como contrapeso da modernidade", como bem o define Carnellas (2008, p. 105).

De alguma forma, nosso posicionamento está ali, impresso. No editorial, no artigo, no direcionamento das entrevistas e na escolha dos entrevistados, nas reportagens, nos 


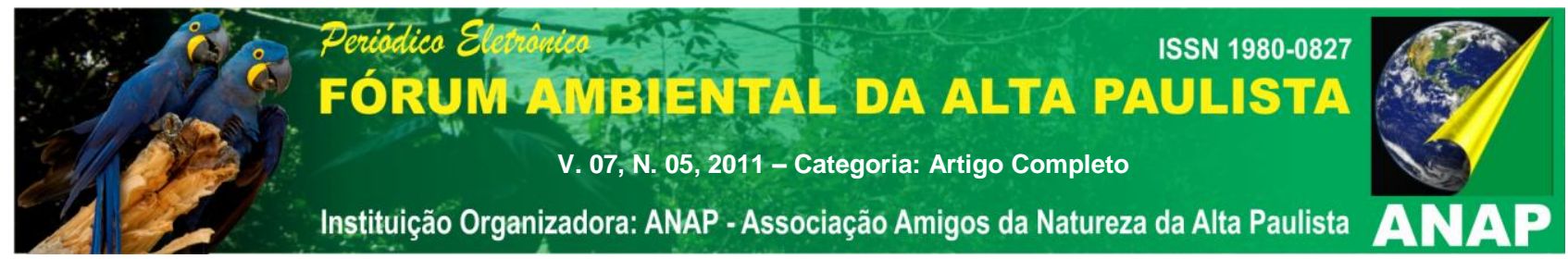

títulos, na própria charge. Se não conseguimos convencer o público leitor a respeito do que sentimos, do que pensamos e das opiniões que formulamos no decorrer da apuração das matérias, acreditamos que levamos alguma informação a pessoas que nunca ouviram falar em Belo Monte. Compartilhando mais uma vez o pensamento de Carnellas (2008, p. 107), acreditamos ainda que, "na melhor das hipóteses, o jornalismo exerceria o papel de fiscal do poder, de denunciador de anomalias que devem ser corrigidas pelas autoridades" e mais, temos que admitir e conviver com o fato de que:

É natural, portanto que a agenda da imprensa gravite sempre em torno dos mesmos temas e do mesmo tipo de enfoque, reverberando escândalos e denúncias, mas deixando de tocar em questões realmente importantes, justamente aquelas que são tão caras à agenda social (CARNELLAS, 2008: p.106).

Para Bucci (2002, p. 26), "se os profissionais puros, altruístas e de boa fé sustentam, antes de tudo, que o jornalismo deveria ser uma práxis ética“, percebemos, com a produção da edição número 13 do jornal-laboratório Arte e Ação, que e de acordo com o que afirma Costa (2009, p. 21):

(...) em público, normativamente, a indústria da notícia se apresenta como a campeã da virtude moral. Mas desanca essa práxis nos bastidores, naquilo que não é escrito nem mostrado, naquilo que está subjacente à investigação, na manipulação e na reutilização da idéia da moral conforme a necessidade, o momento, a situação; para significar isso ou aquilo porque o "interesse público" sempre fala mais alto. Mas o que é interesse público? Quem define o interesse público? A direção da empresa de comunicação? O ocupante do governo da ocasião? O deputado, o empresário, o editor da publicação, o leitor, o consumidor?".

Percebemos, ainda, que o interesse público, no caso da construção da usina Belo Monte, quem define é o governo federal cujo único interesse é resolver o problema de abastecimento de energia elétrica. Para finalizar, vale lembrar que entre os anos de 2001 e 2002, se instaurou no Brasil a conhecida "crise do apagão". Os blecautes atingiram todo o país por falta de geração de energia elétrica, devido ao período de secas intensas, o que deixou os níveis de represas e rios muito abaixo da média. O bug brasileiro fez com que o governo começasse a desenvolver planos de emergência, e, assim, desenterrou antigos projetos para criação de eletricidade, e dentre os projetos, a Usina Belo Monte. 


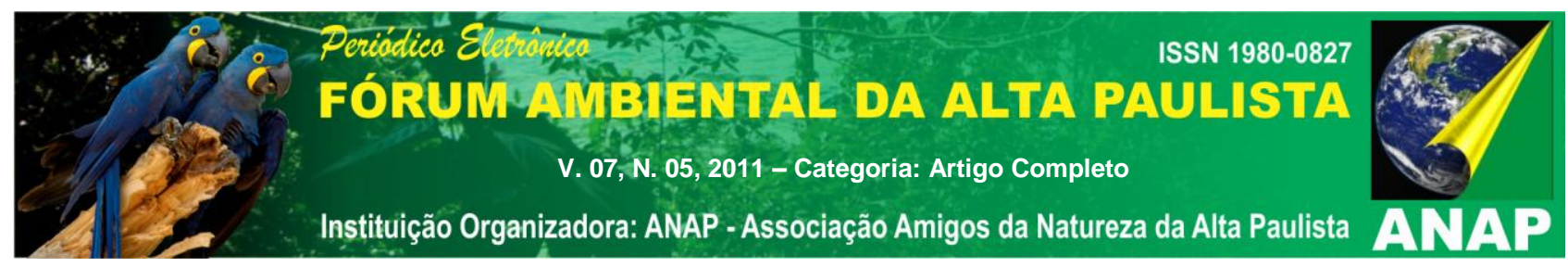

\section{REFERÊNCIAS}

ALCÂNTARA, Norma S. Imprensa na berlinda: a fonte pergunta. 1ª edição. São Paulo: Celebris, 2005.

BREDARIOL, Celso \& VIEIRA, Liszt. Cidadania e política ambiental. 2ª edição. Rio de Janeiro: Record, 2006.

BUCCI, Eugênio. In CANELA, Guilherme (org.) Políticas públicas sociais para o jornalismo. $1^{a}$ edição. São Paulo: Cortez Editora, 2008.

COLLARO, Antonio Celso. Projeto Gráfico: Teoria e prática da diagramação. 4aㅡ edição. São Paulo: Summus, 2000.

COSTA, Caio Túlio. Ética, jornalismo e nova mídia: Uma moral provisória. São Paulo: Editora Zahar, 2009.

CARNELLAS, Marcelo. In CANELA, Guilherme (org.) Políticas públicas sociais para o jornalismo. $1^{a}$ edição. São Paulo: Cortez Editora, 2008.

FERRARI, Maria Helena \& SODRÉ, Muniz. Técnica de reportagem: notas sobre a narrativa jornalística. São Paulo: Summus, 1986.

FREIRE, Paulo. Pedagogia da autonomia: saberes necessários à prática educativa. São Paulo: Paz e Terra, 1996.

LOPES, Dirceu Fernandes. Jornal laboratório: do exercício escolar ao compromisso com o público leitor. São Paulo: Summus, 1989.

LAGE, Nilson. A reportagem: teoria e técnica de entrevistas e pesquisa jornalística. $2^{\underline{a}}$ edição. Rio de Janeiro: Record, 2002.

LASCHEFSKI, Klems; PEREIRA, Doralice Barros e ZHOURI, Andrea (orgs.). A insustentável leveza da prática ambiental: desenvolvimento e conflitos socioambientais. São Paulo: Editora Autêntica, 2005.

MEDINA, Cremilda. Notícia: Um produto à venda - Jornalismo na sociedade urbana e industrial. $2^{\mathrm{a}}$ edição. São Paulo: Summus, 1988.

POLICENO FILHO, Mário Luiz. Jornal-laboratório, uma atividade pedagógica muito além do exercício de marketing. São Bernardo do Campo: Universidade Metodista de São Paulo, Dissertação de Mestrado, 2008.

SATHLER, Luciano \& MARQUES DE MELO, José (org.). Direitos à comunicação na sociedade da informação. São Bernardo do Campo: UMESP, 2005. 


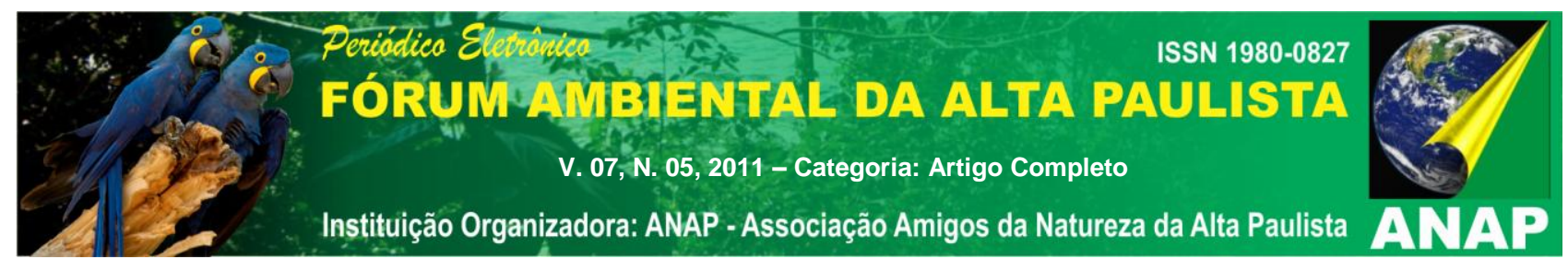

SENRA, Nelson de Castro. O cotidiano da pesquisa. São Paulo: Editora Ática, 1989.

VIEIRA Junior, Antônio. Uma pedagogia para o jornal-laboratório. Tese (Doutorado em Comunicação). Escola de Comunicações e Artes, Universidade de São Paulo, São Paulo, 2002. 